\title{
El Descubrimiento y la Conquista de América en la literatura infantil y juvenil española actual
}

\section{Pedro Mendiola}

Profesor asociado del departamento de Innovación y Formación Didáctica de la Universidad de Alicante. Ha desarrollado su trayectoria investigadora en el ámbito de la literatura hispanoamericana y la literatura infantil y juvenil y su didáctica. Es autor del libro Buenos Aires entre dos calles: breve panorámica de la poesía argentina de vanguardia.

\author{
PEDRO MENDIOLA OÑATE \\ Universidad de Alicante
}

\section{RESUMEN}

Este artículo analiza la imagen de América en la narrativa española infantil y juvenil reciente. El análisis se centra en seis obras que tratan sobre el Descubrimiento de América y que tienen a Colón como protagonista o personaje principal. El estudio se centra en la presencia de tópicos y estereotipos sobre el paisaje de América o la figura del indio.

Palabras clave: América, Colón, literatura infantil y juvenil, novela.

\section{ABSTRACT}

This article examines the issue of America in the recent Spanish children and youth novel. Six works that have to Colon as protagonist or main character are analyzed. This study also examines the loci and stereotypes about the American landscape and the figure of the Indian who featured in these novels.

Keywords: America, Colon, children's and youth literature, novel.

Pancracio Celdrán, en su Gran libro de los insultos, recoge la expresión «hacer el indio» y define su uso pragmático: «A quien se pone en evidencia o hace el ridículo, y quien se deja engañar con facilidad mostrando así su inocencia o falta de malicia decimos que hace el indio». Sobre el origen de esta locución, el mismo autor propone varias posibles genealogías: en primer lugar, que se dijo "en alusión a la facilidad con que los españoles cambiaban oro por las baratijas y menudencias que llevaban desde la metrópoli durante los siglos primeros de la colonización de América»; en segundo lugar, "que deriva de la expresión: «¿Somos indios, o lo hacemos?» con que en el siglo xviII denotaba sorpresa quien era tenido por tonto»; y en tercer lugar, por «la costumbre de los indios de andar semidesnudos y pintarrajeados, en sus bailes y ceremonias, todo lo cual a los occidentales inspiraban curiosidad y risa». Sea como fuere, don Pancracio sitúa el origen de la expresión «hacer el indio»:

En 1892 con motivo de la celebración del IV Centenario del Descubrimiento de América. En aquella ocasión se celebró en

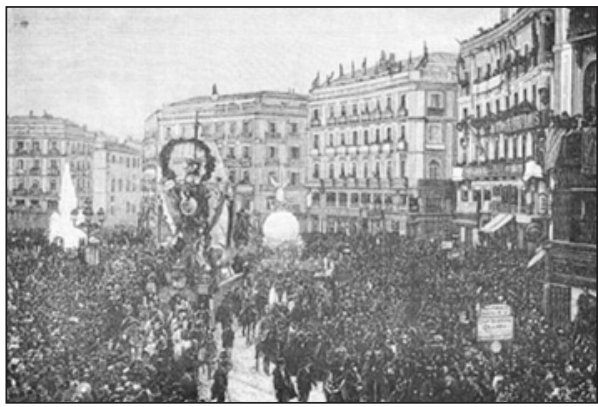

Celebración del IV Centenario del Descubrimiento de América (Madrid, 1892). Madrid una gran cabalgata que recreaba el ambiente del momento con los conquistadores, frailes y soldados de la gran aventura, indios e indias del Nuevo Continente. [...] Fue necesario contratar gran número de personas, la mayoría pobres gentes a las que se les pagó dos duros por salir disfrazados de indios, con taparrabos y lanza, con lo que la pinta de las criaturas causó

El Descubrimiento y la Conquista de América en la literatura infantil y juvenil española actual

PEDRO MENDIOLA OÑATE 


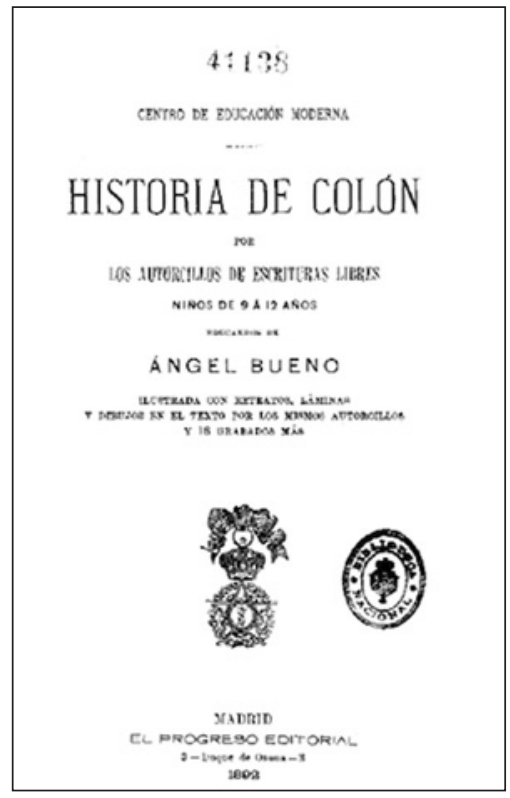

Portada de Historia de Colón. risa, circunstancia por la que se dijo, a quien se quería hacer burla: «Anda y que te den dos duros por hacer el indio» (Celdrán 515-516).

Bajo la dirección del dramaturgo Javier de Burgos y la «puesta en la calle» de Jorge Busato, escenógrafo del Teatro Real, la mencionada cabalgata recorrió las calles de la capital el 13 de noviembre de 1892 (fig. 1). La procesión cívico-histórica se iniciaba con una carroza que representaba la rendición de Granada y culminaba con una gran carroza tirada por diez caballos y precedida por «doce indias y doce indios de las primeras islas descubiertas por Colón» (Blanco 102). En opinión de Alda Blanco, «la estrategia narrativa que se puso en funcionamiento para contar la historia del descubrimiento fue la de comenzar y dar final al relato con la representación de los vencidos» (106).

Podría pensarse que estas representaciones forman parte de una secuencia perdida en el tiempo, que son fruto de un momento y de unas circunstancias determinadas como son las del finales del siglo xIx, que forman parte de un último y simbólico canto elegíaco ante el ocaso del imperio español. Sin embargo, estas imágenes se insertan en una larga tradición de estereotipos y de lugares comunes que han tenido largo recorrido en el pensamiento, el arte y la literatura española.

La literatura infantil y juvenil tampoco ha sido ajena a estas realidades y ha abordado las cuestiones relativas al descubrimiento y la conquista de América desde diferentes puntos de vista. En este estudio se analiza la presencia de estos motivos en la narrativa infantil y juvenil española actual, y se juzga la visión que estas obras ofrecen de la empresa descubridora y del conflicto cultural que esta representa. Para ello, el análisis se centrará en seis obras destinadas al público infantil o juvenil que tratan los albores del Descubrimiento y que tienen por protagonista principal a Colón, o a personajes adyacentes.

\section{La leyenda del Almirante}

El recientemente desaparecido Gabriel García Márquez escribía en un artículo publicado en El País en 1981 que «el diario de Cristóbal Colón es la pieza más antigua de» una literatura, la de América Latina y el Caribe, que desde sus orígenes ha tratado siempre de plasmar una realidad que «iba más lejos que la imaginación». Y cuatro lustros antes que el Nobel colombiano, Joaquín Balaguer, escritor y político dominicano, había visto también en Colón a un «precursor literario» (1949) cuyas cartas y diarios habrían de condicionar las posteriores miradas hacia el hombre y la naturaleza del nuevo continente.

A pesar de que los textos colombinos fueron editados en vida del Almirante y traducidos a diversos idiomas, no sería hasta 1825 en que Martín Fernández de Navarrete publica una amplia recopilación documental con sus cartas y diarios, cuando Colón y sus circunstancias desembarcarían definitivamente en la imaginería literaria. Cierto es que la historiografía ilustrada europea había ya puesto sus ojos en las empresas colombinas a través de la Historia de América (1777) del escocés William Robertson, o la denominada Historia de las dos Indias (1770) del abate Raynal, o la inconclusa Historia del Nuevo Mundo (1793) encargada por Carlos III al americanista valenciano Juan Bautista Muñoz como respuesta a las interpretaciones foráneas. Sin embargo, el interés literario por la aventura del descubrimiento, sus personajes y una naturaleza de renovadas proporciones, no fecunda, como decía, hasta el siglo XIX, en torno al movimiento romántico.

Dos hitos en esta construcción de Colón como héroe literario los encontramos en las obras de dos importantes autores románticos norteamericanos: el ensayo Historia de la vida y viajes de Cristóbal Colón (1828) de Washington Irving, y la novela Doña Mercedes de Castilla o el viaje a Catay (1840) de Fenimore Cooper, publicadas en Londres $\mathrm{y}$ en Boston, respectivamente, y que fueron traducidas y editadas en España de manera casi inmediata. Luego vendrían Lamartine, León Bloy e incluso Julio Verne para acabar de configurar la «leyenda colombina», como la definieran José María Asensio (1892), Menéndez Pelayo o Fernández Duro (Bernabeu Albert 114).

En el ámbito hispánico, la fecha de 1892 y sus aledaños genera el primer gran impulso bibliográfico sobre Colón y las circunstancias del descubrimiento: un sinfín de estu- 
dios, ensayos, álbumes, mapas, poemas épicos, catálogos, iconografías y documentación de todo pelaje. Con el titulillo de «Colón y compañía» definía irónicamente Clarín (243) a esta desmesura bibliográfica:

De Colón nada malo tengo que decir; pero de la Compañía, francamente, va uno estando harto.

Y no me refiero a los Pinzones ni a las calaberas, como las llamaba un orador del Ateneo. Me refiero a los eruditos de Centenario en ristre, a los parásitos de la celebridad.

Las conmemoraciones por el IV Centenario dejarán también los primeros intentos por hacer llegar la gesta descubridora al público infantil, principalmente a través de las publicaciones periódicas dirigidas a los niños. Se trata, en general, de textos de divulgación histórica o de carácter instructivo, con escaso o nulo aliento literario, y con un propósito de clara exaltación patriótica. Un juicio exhaustivo de estas referencias requeriría evidentemente de un estudio pormenorizado que escapa a este trabajo, aunque puede mencionarse a modo de ejemplo la serie titulada "Colón. Centenario del descubrimiento de América» de Eusebio Martínez de Velasco. Estos artículos se publicaron entre marzo y octubre de 1892 en la revista madrileña La edad dichosa que, bajo el subtítulo de «Revista ilustrada de instrucción y recreo para niños y niñas», estaba dirigida por Carlos Frontaura, pionero de la prensa periódica infantil en España.

Y una muestra especial la encontramos en la singular Historia de Colón escrita por «los autorcillos de Escrituras libres» (fig. 2). Esta publicación, de corte puramente encomiástico, se declara escrita e ilustrada por niños de 9 a 12 años, alumnos del maestro Ángel Bueno del Centro de Educación Moderna para niños huérfanos. Ángel Bueno ya había publicado otro volumen escrito por escolares titulado Escrituras libres, ampliamente celebrado por la prensa pedagógica del momento, y que respondía a la denominada "pedagogía moderna», heredera de los movimientos de renovación didáctica desarrollados en Europa desde mediados del siglo xviI por Comenius, Pestalozzi o Herbart. Citaré un pequeño fragmento de la imagen idílica que se ofrece del territorio americano porque la encontraremos de forma repetida en buena parte de las publicaciones analizadas: «Los viajeros estaban sorprendidos; nunca habían visto cosa parecida de hermoso; altísimo follaje, árboles gigantes, cielo despejado...» (Bueno 69).

Un siglo más tarde, la conmemoración del V Centenario provocará una nueva catarata bibliográfica, aunque en este caso, como hiciera notar García Padrino (556), ya hay una interesante producción de carácter infantil y juvenil a la que prestar atención. Buena parte de la bibliografía que analizaremos se origina por tanto en torno a dos fechas conmemorativas: 1992, V Centenario del Descubrimiento; y 2006, V Centenario de la muerte de Cristóbal Colón.

Cuando no modelo literario, Colón ha sido, desde luego, el referente por antonomasia de la literatura inspirada en el Descubrimiento. No es de extrañar, por tanto, que buena parte de la bibliografía literaria que trata sobre el descubrimiento y la conquista de América, también en el ámbito infantil y juvenil, gire en torno a su figura. Es significativo también que Colón sea uno de los protagonistas prototípicos de la denominada «nueva novela histórica» (Menton) producida en América Latina desde fines de los años 70.

En el ámbito estrictamente infantil, no faltan en la actualidad las publicaciones dedicadas a la figura de Colón. En estas dominan las ilustraciones y el componente lúdico, y la historia, muy simplificada, suele arrancar de un Colón niño que muestra una especial predisposición hacia la aventura. Podemos citar entre otros: El viaje de Cristóbal Colón (2005) de Anna Obiols, con ilustraciones de Subi; El gran viaje de Colón (2006) de Mikel Valverde; El buevo de Colón (2005) de Violeta Monreal; o ¿Quién era Cristóbal Colón? (2006) de José María Plaza (fig. 3). Entre estos títulos abundan las muestras de la denominada por Juan Cervera (159) «literatura instrumentalizada», puesta al servicio de algún personaje serializado o de algún objetivo supuestamente didáctico.

Analizaré brevemente los libros de Violeta Monreal y José María Plaza. Ambos parten del Colón niño y cuentan un periplo que tiene su cénit en el Descubrimiento. Aunque
El Descubrimiento y la Conquista de América en la literatura infantil y juvenil española actual

PEDRO MENDIOLA OÑATE 


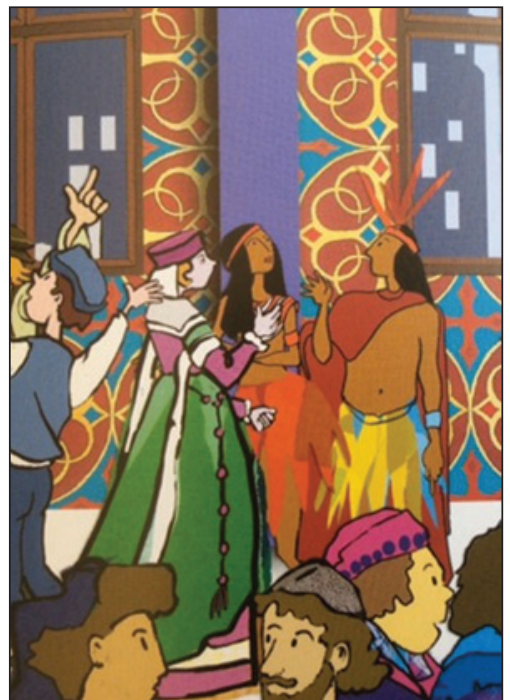

llustración de El huevo de Colón.

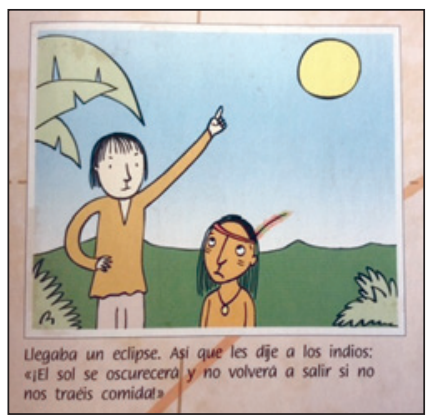

llustración de El huevo de Colón.

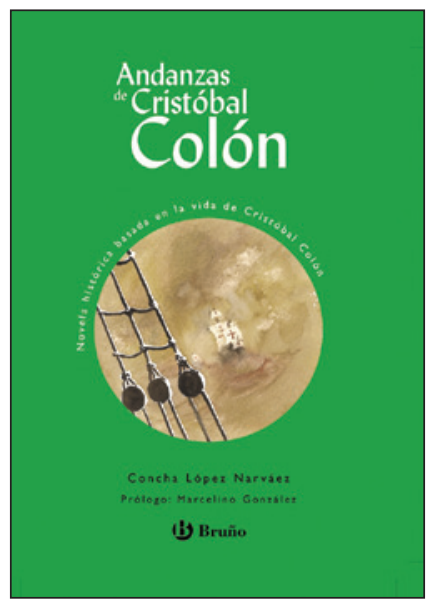

Cubierta de Andanzas de Cristóbal Colón. en las ilustraciones es perceptible el crecimiento del personaje, la imagen del Colón descubridor es la de un joven que poco se aviene con los 56 años que tendría el Almirante cuando emprende el viaje hacia las Indias.

En El huevo de Colón de Violeta Monreal, dirigido a niños de 6 a 9 años, las ilustraciones llevan el peso principal del relato, narrado en primera persona, que se declara «basado en el diario de navegación que Cristóbal Colón escribió día a día en su primer viaje». La inevitable distancia temporal y cultural entre el tiempo relatado y el tiempo del lector es aprovechada por la autora para proponer un juego fundamentado en el anacronismo. De hecho en la cubierta trasera del libro se advierte de que solo es apto "para detectives con mucha experiencia». La autora se sirve de la conocida anécdota colombina del huevo puesto en pie como motivo vertebrador de la historia. Este suceso a todas luces apócrifo, según informa Fernández de Navarrete (CXLIICXLIII), parece tener su origen en los grabados de Théodore de Bry de 1594 para su obra America pars Quarta, y haber sido difundido desde el siglo XIX por el historiador italiano Luigi Bossi.

Por otro lado, el libro de José María Plaza, catalogado por la editorial para lectores a partir de 6 años, pese al poco halagüeño convencional título de ¿Quién era Cristóbal Colón?, se asienta en una mayor carga literaria que combina la narración en tercera persona, el diálogo y la primera, en los pasajes que podrían relacionarse directamente con los diarios de viaje. El distanciamiento temporal entre el enunciado y el tiempo de la enunciación queda determinado por el íncipit del libro: «Érase una vez un niño que se llamaba Cristóbal». Pero además, la elección de esta fórmula tradicional de apertura representa, en cierto modo, una retraimiento del componente histórico y una invitación al lector para entrar en «ese otro mundo» (Morote Magán 181) que es el territorio de los cuentos.

El libro, que ha sido ilustrado por la hispano-alemana Natascha Rosenberg, contiene un juego de la oca en las hojas de guarda y otros juegos integrados en la narración. Por otro lado, podría considerarse este libro como una versión simplificada de la novela juvenil ¡Tierra a la vista!, del mismo autor, de la que hablaré más adelante. Ambos libros coindicen en los puntos fundamentales del relato, en la caracterización general del protagonista y en las anécdotas seleccionadas, como la del eclipse que supuestamente predijo el Almirante en su cuarto viaje para asombrar a los indios de Jamaica (fig. 4). Este es un episodio fabuloso que recogió en 1536 el escribano Diego Méndez de Segura (325) en su testamento, y posteriormente Hernando Colón en la biografía de su padre (1571), y que tal vez es el germen de una aventura similar narrada por Mark Twain (fig. 5) en su novela Un yanqui en la corte del rey Arturo (1889).

Entre las obras destinadas al público juvenil, analizaré en este primer apartado cuatro novelas cuyo hilo conductor es la figura del Almirante, su personalidad y sus gestas: iTierra a la vista! (2005), de José María Plaza; ¡Polizón a bordo! (el secreto de Colón) (2005), de Vicente Muñoz Puelles; Andanzas de Cristóbal Colón (2006) de Concha López Narváez; y Y le llamaron Colón (2006), de Jordi Sierra i Fabra.

El pasado histórico «aunque por su propia condición parece inmodificable, está, sin embargo, tan entreverado de brumas y mitos, que resulta el mejor de los decorados exóticos, y hábilmente ordenado, puede apoyar firmemente la certidumbre de cualquier aventura, siempre que el héroe sea atractivo y se encuentre en trance de correr toda clase de riesgos». No se refiere José María Merino (56) en esta cita de forma específica a la figura de Colón, pero en el relato de su vida podría encontrar un novelista todos los elementos de los que habla Merino: origen oscuro, secretos, obsesiones, incertidumbres, piratas, naufragios, viajes, aventuras, paisajes desconocidos...

Evidentemente, el género literario predominante en estas obras es el de la novela histórica, un género, por otro lado, de gran arraigo en la literatura juvenil española desde los años 80 del siglo xx como destaca García y juvenil española actual 
Padrino (555-556). En opinión de Thaler y Jean-Bart no es extraño que la literatura juvenil haya adoptado este género literario de origen adulto pues:

l'Histoire représente par excellence un espace et un temps héroïques où tous les obstacles sont surmontables, tous les succès posibles, loin des contingences du pésent: une sorte d'âge d'or où les rêves son vécus sur le mode triomphal (43-44).

No obstante, este juicio acarrea una primera contradicción, ya que el marco histórico del héroe es esencialmente adulto. La solución del narrador es medianamente sencilla: o bien sitúa la acción histórica en la infancia o la adolescencia del héroe, revistiéndole de los mismos atributos que se supone tendría de adulto (la osadía, el deseo de aventura, etc.); o bien coloca cerca del personaje histórico adulto a un héroe secundario ficcional, niño o joven, que si por un lado se impregna de las cualidades del héroe, por otro, funciona como complemento o incluso como contrapunto del personaje histórico. Concha López Narváez coincide en que la edad de los personajes protagonistas en la novela histórica juvenil es de suma importancia, «ya que son los protagonistas los que van a conducir a los lectores hasta un tiempo muy lejano, y es por eso conveniente que la edad sea un punto de encuentro y no de distanciamiento» («Visión personal de la novela histórica y de su proceso de creación» 23).

Con respecto a la caracterización del protagonista, podemos establecer precisamente una primera distinción en este grupo de obras entre las que tienen como protagonistas al propio Colón (las de José M. a Plaza y Sierra i Fabra) y aquellas en las que el peso de la narración recae en algún epígono: generalmente algún muchacho enrolado entre la marinería de las carabelas (las de López Narváez y Muñoz Puelles).

La primera de las novelas que abordaré es Andanzas de Cristóbal Colón (2006) de la mencionada Concha López Narváez (fig. 6). La autora, licenciada en Historia de América, es una de las más prolíficas escritoras españolas de la literatura infantil y juvenil. En su obra se destacan sobre todo las novelas con trasfondo histórico y las adaptaciones de clásicos de la literatura española.
El título de la novela corresponde en parte al de una colección de la editorial Bruño de la que forman parte otros diez títulos entre los que, desde luego, no pueden faltar: don Quijote y Sancho, Lázaro de Tormes, el Cid, el Conde Lucanor, Rosaura y Segismundo o los héroes del 2 de Mayo. No obstante, el término «Andanzas», tal vez pueda ser un primer indicativo para ilustrar al lector sobre el terreno literario que pisa. «Andanzas» define la Academia como «vicisitudes, peripecias o trances», es decir: «Alternativa de sucesos prósperos y adversos», cambio repentino en el estado de las cosas y «momento crítico y decisivo por el que pasa alguien» (2001). Desde luego, si hay una historia que puede identificarse con el término «andanza» es la de Cristóbal Colón. Aunque es esta una voz no exenta de cierta carga literaria en la que resuenan desde Quevedo, Pío Baroja y Unamuno, hasta Sánchez Ferlosio o Camilo José Cela.

Sin embargo, pese a lo que en un primer momento pudiera hacer presagiar el título, la novela no aborda la novelesca biografía de Colón, sino que arranca con la llegada del navegante a tierras españolas en 1485, curiosamente el mismo año en que nacía en Medellín, Extremadura, otro de los grandes personajes españoles relacionados con América: Hernán Cortés.

A lo largo de XVII capítulos y un epílogo, la novela narra los acontecimientos referidos al primer viaje de Cristóbal Colón: su llegada a España, las negociaciones con la Corona, los preparativos de la expedición, la odisea del viaje, la llegada a América, el conocimiento de los pueblos indígenas y el regreso a España. El último capítulo resuelve en un par de páginas el resto de viajes colombinos y la muerte del Almirante. El epílogo, por otro lado, cumple una función metaliteraria donde la autora informa al lector sobre algunos elementos referidos a la fidelidad histórica y la verosimilitud de los dos personajes que van adquiriendo mayor peso narrativo conforme avanza la historia: Andrés y Anoa.

En el primer capítulo se introduce al personaje de Andrés Ximénez de Moguer, un muchacho «de diez u once años» (López Narváez, Andanzas de Cristóbal Colón 13) con un don para imitar voces y sonidos que a la postre le servirá para comunicarse con los habitantes de las descubiertas tierras americanas.
El Descubrimiento y la Conquista de América en la literatura infantil y juvenil española actual

PEDRO MENDIOLA OÑATE 


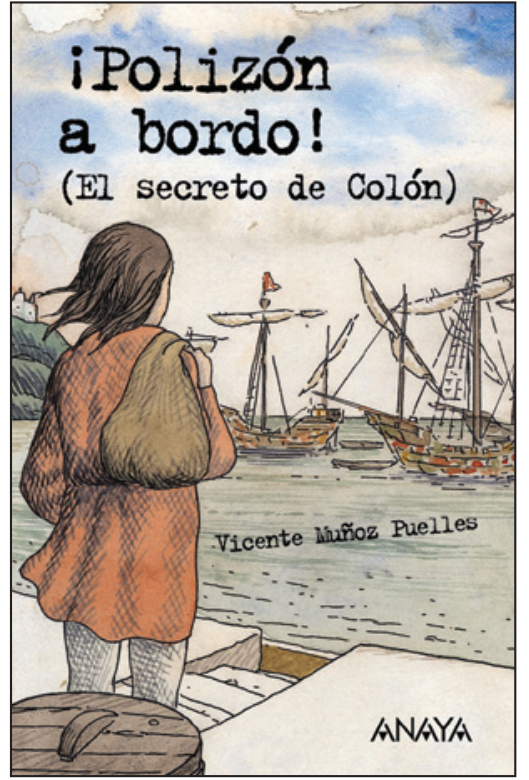

Cubierta de Polizón a bordo.

El Descubrimiento y la Conquista de América en la literatura infantil y juvenil española actual

PEDRO MENDIOLA OÑATE
Andrés, que tiene las mismas ansias de aventura de un Colón adolescente: «¿Sabéis qué es lo que sueño? Pues que llego muy lejos, lejísimos, $\mathrm{y}$ sin poner un pie sobre la tierra. Lo que deseo, más que nada en el mundo, es navegar» (López Narváez, Andanzas de Cristóbal Colón 15). Andrés, por encima de Colón y el resto de la marinería, acabará por convertirse en el personaje mejor definido de la novela, mientras que Colón aparece casi como un "personaje plano», o flat character, siguiendo la terminología de E. M. Forster (75), un personaje caracterizado sin aristas, sin dobleces, cuya personalidad ofrece una faceta única representada por dos obsesiones: el brillo del oro y haber llegado a las costas de Asia. Además, el personaje de Andrés sirve de contrapunto al de Colón no solo por su falta de codicia, sino por su voluntad de comprensión de la lengua, la realidad y la cultura de los pueblos indígenas, cuestiones estas, por otro lado, como recuerda Tzvetan Todorov (2003) que jamás interesaron a Colón más allá de lo que pudiera contribuir a sus propósitos y determinaciones.

Ya se han mencionado algunos de los signos de historicidad de los que se sirve la autora para situar al lector en un tiempo pretérito: un protagonista ilustre, un acontecimiento histórico perfectamente conocido, fechas, lugares, etc. Menos reconocibles quizá para un lector juvenil sean las fuentes documentales que utiliza la novelista para afianzar la historicidad de la narración; aunque Concha López Narváez no se esfuerza demasiado en ocultar que los Diarios de Colón recopilados por Bartolomé de las Casas, y sobre todo la controvertida Historia del Almirante de Hernando Colón, segundo hijo del descubridor, sustentan el fundamento histórico del relato. En este caso, algunas referencias aparecen tomadas de forma casi literal, como las referentes al denominado "predescubrimiento de América»: es decir, los indicios, sospechas, informaciones e investigaciones que supuestamente hicieron pensar a Colón en la existencia de una ruta occidental hacia las Indias. Tesis esta que puso en boga el historiador español Juan Manzano (1982) a finales de los años 70 .
La autora se mantiene fiel también a las fuentes documentales en cuanto a la imagen que se ofrece de las tierras americanas. Si la famosa «Carta a Luis de Santángel» y los diarios de Colón inauguraban la visión paradisiaca de América (aunque hay que recordar que el conocimiento colombino del continente americano se circunscribe al territorio caribeño), la descripción que ofrece López Narváez no se aparta del tópico del locus amoenus, que aparece perfectamente definido en el relato de la llegada a tierra en el capítulo XII: cielo azul, mar tranquilo, aguas transparentes, arenas doradas y suaves, árboles verdes y floridos, pájaros cantores, etc.

Finalmente, con la relación amorosa entre Andrés y Anoa, hija de un cacique isleño, la novela deriva hacia cuestiones de evidente anacronismo ideológico y cultural como la defensa del mestizaje y de la interculturalidad, pero que representaría tal vez ese anacronismo necesario al abordar literariamente la realidad histórica del que hablara Hegel: «La sustancia interna de lo representado sigue siendo la misma, pero el mayor desarrollo cultural hace necesaria una transformación en la expresión y en la figura» (202). En este sentido, hemos de entender este anacronismo como una licencia para acercar el acontecimiento histórico a los valores y la concepción del mundo propia del lector adolescente actual, sin desmerecer por ello la verosimilitud. En este mismo sentido, la propia autora revelaba algunas de las estrategias de las que se vale el autor de novelas históricas juveniles para acercar los periodos históricos lejanos al lector joven actual, que pasan principalmente por «buscar constantes en el espacio y el tiempo»: «Las emociones tienen mayor fuerza que la aventura, porque la aventura va revestida con ropajes propios, y las emociones no tienen ropajes» (López Narváez, «Visión personal de la novela histórica» 23).

La segunda de las novelas es iPolizón a bordo! (El secreto de Colón) (2005) del novelista valenciano Vicente Muñoz Puelles (fig. 7). Conviene advertir que Muñoz Puelles es un perfecto conocedor de la historiografía del Descubrimiento y de la figura de Colón. A la figura del descubridor había ya dedicado un ensayo de carácter biográfico titulado Yo, Colón (1991) y una interesante novela para adultos titulada El último manuscrito 
de Hernando Colón (1992). Como en el caso de Andanzas..., esta novela tiene por protagonista a un acompañante de Colón, en este caso, como indica el título, se trata de un joven polizón con ansias de aventura que logra introducirse en la bodega de una de las carabelas.

Literariamente, es una novela más compleja que la anteriormente analizada. Ya no estamos ante una secuencia lineal de la historia, sino que la narración arranca de la muerte de Colón en 1506, y el protagonista, a modo de racconto, retrocede hasta su niñez para contar su caso, y rememorar su aventura juvenil junto al navegante genovés. El inicio de la novela sigue claramente el modelo de la novela de aprendizaje, y son perceptibles las referencias implícitas a la novela picaresca y al Lazarillo, tanto en la descripción de personajes y ambientes como en las ilustraciones.

Es evidente que la precisión histórica no es la principal preocupación de Muñoz Puelles al componer su novela. Inventa personajes y situaciones, circunstancia esta que en absoluto es extraña a la naturaleza de la ficción histórica, aunque en determinados pasajes la licencia se convierte en subversión: como cuando convierte a Gonzalo en amanuense del diario de abordo, e incluso le concede la gloria de haber sido el primero en avistar ¡tierra!

Como en la novela anterior, hay una identificación inicial entre el inquieto protagonista y un aventurero Colón adolescente. Sin embargo, la mirada de Gonzalo nos ofrece un retrato del Almirante bastante alejado de la idealización. Colón se presenta como un personaje contradictorio y en algún momento enredador y mendaz, capaz de sorprender al lector con sus acciones o sus pareceres. $\mathrm{Al}$ contrario que en la novela de López Narváez, Colón se muestra en la obra de Muñoz Puelles como un personaje «redondo", siguiendo la citada terminología de Forster: «Un personaje redondo trae consigo lo imprevisible de la vida», decía Forster (84). Además, Gonzalo insinúa esa condición de fundador literario de la realidad americana de la que hablaba García Márquez: «Tejía historias como su padre tejía telas. Había tenido que convertirse en una suerte de fabulador», dice Gonzalo (Muñoz Puelles, ;Polizón a bordo! (El secreto de Colón) 88). Esta misma idea aparecía ya en El último manuscrito... cuando Hernando Colón distingue a su padre como un «há- bil urdidor de fábulas» (Muñoz Puelles, El último manuscrito de Hernando Colón 20). Pero la narración histórica, como decía José María Merino, es un género «entreverado de brumas y mitos» (56).

Al igual que López Narváez, Muñoz Puelles utiliza como referente histórico dos fuentes que conoce a la perfección: los diarios colombinos y la biografía de Hernando Colón, cuyas referencias se incorporan en ocasiones de forma casi literal en la narración. También hay interesantes muestras de intertextualidad, como la referida a la expulsión de los judíos en la que resuenan inevitablemente los shakespearianos lamentos de El mercader de Venecia: «¿Acaso no eran como nosotros? [...] ¿No acariciaban, como yo, ilusiones y esperanzas?», dice Gonzalo; «Si nos pincháis, ¿no sangramos...?», había dicho el judío Shylock.

La llegada a América queda revestida de la misma imagen de belleza tranquila bosquejada por López Narváez: el «agua cristalina», «los altos árboles», la bruma retirada, la arena blanca y ligera como la harina, etc.

Estas dos novelas además tienen una evidente proyección escolar, pues ambas incluyen una propuesta de actividades como ampliación o suplemento de la lectura. La de López Narváez en un apéndice al final del libro y la de Muñoz Puelles en un cuadernillo que acompaña al ejemplar con actividades que combinan lo lúdico (sopa de letras) y lo didáctico, centrado en la comprensión lectora, la expresión escrita, la ampliación de contenidos y la lectura extensiva.

Las otras dos novelas que sí tienen como protagonista principal a Colón, muestran bastantes diferencias entre sí.

La primera de ellas, ;Tierra a la vista!: la bistoria de Colón (2005) del periodista y escritor burgalés José María Plaza, es una obra curiosa. A pesar del título, la historia se centra más en la figura de Colón, su infancia, su mocedad, su periplo por Portugal y España, que en la propia cuestión del Descubrimiento. De hecho, según declara el autor, este libro «no es una biografía ni una novela, sino una historia: la historia de Cristóbal Colón» (Plaza ; Tierra a la vista! 200); entendiendo el término historia, hemos de suponer, como el «conjunto de los acontecimientos ocurridos a alguien a lo largo de su vida o en un período de ella» (RAE). El libro se inicia también
El Descubrimiento y la Conquista de América en la literatura infantil y juvenil española actual

PEDRO MENDIOLA OÑATE 


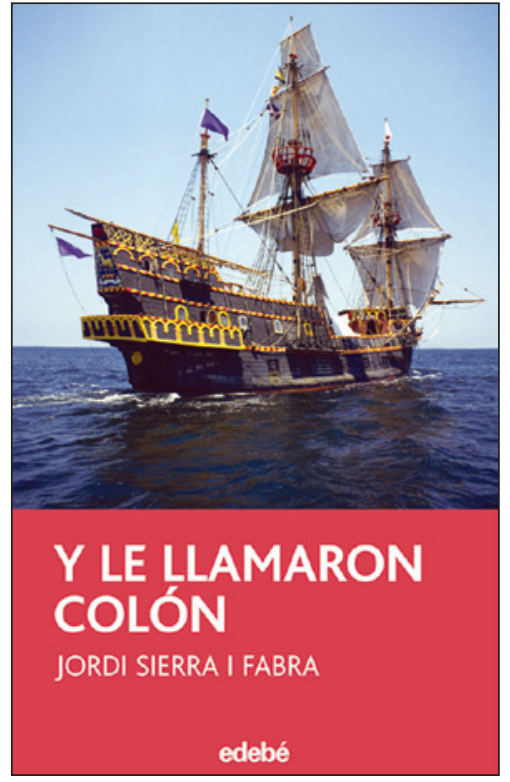

Cubierta de Y le llamaron Colón. con la tradicional fórmula: «Había una vez un niño que vivía...»; y culmina con su muerte.

De todas las obras analizadas es quizás la más cercana a una corriente denominada nueva novela histórica de gran auge en la narrativa latinoamericana posterior a los años 70 . En ella se dan algunas de las características enumeradas por Seymour Menton (42-46) en su ensayo sobre esta tendencia literaria: la distorsión consciente de la historia, la ficcionalización de personajes históricos, el humor paródico (al que contribuyen también las ilustraciones de Jvlivs), pero sobre todo el juego intertextual. En el anexo que acompaña la obra, el autor propone al lector descubrir una serie de «homenajes» a diversos poetas tanto españoles como latinoamericanos. Se trata de versos generalmente puestos en boca de Colón y que van desde Juan Ramón Jiménez o Machado, a Rubén Darío, Amado Nervo, Borges, Neruda, César Vallejo o Nicolás Guillén. Seguramente la referida al poeta cubano sea la más divertida de estas referencias, pues Plaza identifica la lengua de los indígenas americanos con el conocido estribillo de «Sensemayá» de Guillén y con otros cantos de la tradición oral afrocubana: «¡Mayombe-bombe-mayombé-sensemayá! ¿Prácata-para-pa?» (Plaza ;Tierra a la vista! 119).

La última de las novelas, $Y$ le llamaron Colón (fig. 8) de Jordi Sierra i Fabra, es la más atípica de todas las obras estudiadas. Aun estando la novela dedicada a «mis hermanos de los pueblos indígenas de América», los hechos relativos al Descubrimiento apenas son mencionados, puesto que la historia se centra en los años mozos de Colón en Italia, una etapa desconocida, según su autor, «de la vida del futuro descubridor de América» (Sierra i Fabra 185).

La novela de Sierra i Fabra, con su estructura retrospectiva y su particular estilo narrativo, responde al modelo de la novela de aventuras dentro de un marco histórico. La aventura por tanto prima sobre los datos históricos, que son omitidos, reelaborados o elucubrados según las necesidades de la peripecia narrativa. El grueso de la novela gira en torno a una historia de amor imposible que vive el joven Cristóforo con una joven española y sobre el llamado «secreto de Colón» que presupone una pre-idea de América a través de indicios y presunciones (como la existencia del piloto anónimo que da cuenta de lejanas o desconocidas tierras allende los mares, o el conocimiento de la obra del cosmógrafo Paolo Toscanelli). Sierra i Fabra se toma además muchas licencias históricas, como la imaginada relación entre Colón y Leonardo da Vinci, o Amérigo Vespuccio que poco o nada aportan al desarrollo de la trama.

\section{«Luego vinieron gente desnuda...»}

Si los escritos de Colón inauguran una imagen idealizada de la naturaleza americana, que será repetida hasta la saciedad, en crónicas, dramas, poemas y novelas en los siglos sucesivos, la mirada colombina sobre el indígena caribeño también se convertirá en un tópico recurrente que tuvo su momento álgido en el siglo XviII, pero que el pensamiento y la literatura europea ha ido arrastrando hasta nuestros días. Todorov considera que «el descubrimiento de América, o más bien el de los americanos, es sin duda el encuentro más asombroso de nuestra historia» (14). De hecho, de entre todas las «maravillas» que trajo Colón a su regreso a España (algodón, maíz, patatas, tabaco y un poquito de oro), sin duda fue el grupo de indígenas lo que habría de causar mayor conmoción en el pensamiento europeo. De inmediato, el indio americano se incorpora al imaginario artístico europeo. Es significativo que ya en 1494 encontremos una de las primeras representaciones pictóricas del indio americano, quizá la primera, en un fresco del Vaticano titulado Resurrección de Cristo, del pintor renacentista italiano Pinturicchio (Paolucci).

En la novela de López Narváez, por ejemplo, el personaje de Colón confiesa a Andrés la gran importancia de llevar «a España algunas personas de las islas. Es necesario que los Reyes vean, por sí mismos, que son gentes pacíficas y generosas, y que oigan de sus labios cómo son sus costumbres y sus tierras» (Andanzas de Cristóbal Colón 133). Similar relato aparece en iTierra a la vista! aunque José María Plaza insinúa que la presencia de indios esclavos en las naves 
de regreso fueron una solución de urgencia del Almirante para contentar a los reyes ante el escaso oro recaudado. La imagen en cualquier caso es la esperada: plumas, taparrabos, loros y papagayos (fig. 9).

Por otro lado, Colón había subrayado en sus diarios el carácter amable, tranquilo, sumiso y dócil de los primeros pueblos que encontrara: son «buenos servidores», determina Colón. Y la versión colombina se vería completa por la de su glosador, fray Bartolomé de las Casas, que consideraba a los indígenas «ovejas mansas» (143), humildes, pacíficas, delicadas, inocentes e infantiles, y débiles para el trabajo. Colón y Las Casas, entre otros, estaban sentando las bases del concepto de «buen salvaje», que será uno de los argumentos que utilizarán los deterministas ilustrados franceses e ingleses, principalmente, para decretar la decadencia y la inferioridad de la naturaleza y del ser americano. Voltaire, por ejemplo, contribuyó decisivamente a difundir el tópico del indio caníbal; Marmontel consideraba a los indios «débiles de espíritu y de cuerpo»; para Corneill de Paw los indios eran «como muchachitos encanijados, incurablemente perezosos e incapaces del menor progreso mental»; o el abad Raynal que describía a los hombres americanos directamente como «menos fuertes, menos valientes; sin barba y sin pelo; degradados en todos los signos de la virilidad» (Gerbi 61-62). Tampoco escapan las obras estudiadas a alguno de estos tópicos: «Pobres gentes, a quienes todos llamaban indios», leemos en López Narváez (Andanzas de Cristóbal Colón 147); "pacíficos indígenas» e «indios mansos», en José María Plaza (jTierra a la vista! 142), o en la misma obra: «iSon estúpidos estos indios!» (122), dice un hermano Pinzón al otro, cuando un nativo toma una espada por el filo y se corta la mano.

La desnudez, regresando a la prefiguración colombina del indígena americano, fue el primer elemento que llamó la atención del Almirante y de sus hombres. En Europa, trata de explicar José María Plaza en ;Tierra a la vista! (fig. 10), «se medía el grado de civilización y la clase social por el vestuario, así que dedujeron que estaban ante un pueblo muy primitivo» (2005, p. 119). La cuestión de la desnudez es un elemento recurrente en lo relativo a lo que Todorov denomina el descubrimiento del otro (44). Aparece reflejada en casi todas las obras analizadas, aunque solo Concha López Narváez trata de superar lo anecdótico, y propone una lectura de entendimiento intercultural:

los españoles no les quitaban ojo, y también estaban asombrados, pues, para comenzar, iban todos desnudos, aunque su desnudez era algo tan sencillo y natural que a nadie avergonzaba, y de ningún modo les parecían ridículos o deshonestos. Se asombraban porque no eran la clase de personas que pensaban encontrar en las tierras riquísimas de Asia (Andanzas de Cristóbal Colón 101).

Otro de los tópicos que simbolizan la superioridad del europeo frente al indígena americano es lo ventajoso del trueque, como vimos al principio. Así lo expresaba Colón en su diario el 13 de octubre: «Mas todo lo que tienen lo dan por cualquier cosa que les den; que hasta los pedazos de las escudillas y de las tazas de vidrio rotas rescataban» (32). Este aspecto lo recogen también Muñoz Puelles y José María Plaza y de nuevo Concha López, trata de explicar esta circunstancia desde un punto de vista cultural: «Compartir era algo natural en aquellos lugares. Tuvieran mucho o poco, todos compartían, lo que no acababan de entender los españoles» (Andanzas de Cristóbal Colón 121). No obstante, este pasaje responde también a esa «visión del Paraíso» que tuvo Colón, y a todo el discurso utópico renacentista que los cronistas de Indias vincularon insistentemente con el Nuevo Mundo.

\section{Conclusiones}

Técnicamente, en cuanto a la ficcionalización de los personajes, la intertextualidad o la mitificación del acontecimiento histórico, estas novelas, salvo alguna excepción, están más cerca de la novela histórica clásica, o de la novela histórica romántica, caracterizadas por Georg Lukács en su pionero estudio sobre este género narrativo, que de la ya mencionada «nueva novela histórica» latinoamericana, de la que son coetáneas.
El Descubrimiento y la Conquista de América en la literatura infantil y juvenil española actual

PEDRO MENDIOLA OÑATE 


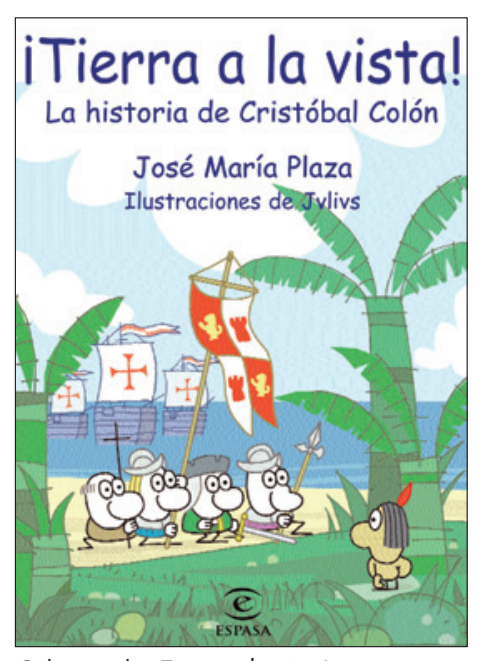

Cubierta de ¡Tierra a la vista!.
Aun así, es notable la renovación de temas y tratamientos literarios experimentada por la narrativa para niños producida en España a partir de los años 60, que se plasma especialmente, según García Padrino, en la actitud de los autores hacia los acontecimientos históricos sobre los que no se adopta ya «un tono épico ni grandilocuente para exaltar un pasado glorioso o imperial» (534). En vez de eso, la figura de Colón aparece generalmente cuestionada, aunque en muchos casos los hechos históricos de mayor truculencia quedan dulcificados o, directamente, silenciados. La visión general que se ofrece del Descubrimiento es la de una gran aventura, mientras que la conquista resulta apenas el inicio de un inevitable proceso más o menos amable de asimilación.

La figura del indio representa el otro gran personaje de estas novelas. Aparece generalmente como un personaje plano, que manifiesta cierta pasividad ante los hechos narrados, y que salvo alguna bienintencionada tentativa de comprensión, como en la novela de López Narváez, aparece caracterizado con atributos similares a los perpetuados por el imaginario europeo inaugurado por los diarios de Colón.

\section{Bibliografía}

Alas, Leopoldo (Clarín). Palique. Madrid: Librería de Victoriano Suárez, 1893.

Asensio, José María. «La leyenda colombina». El Centenario. Revista ilustrada. Madrid: Tipografía de «El progreso editorial», Tomo II: 193-205.

Balaguer, Joaquín. «Colón, precursor literario2, Thesaurus. Boletín del Instituto Caro y Cuervo, Bogotá: Tomo V, núms. 1, 2 y 3, (1949): 372-385.

Bernabeu Albert, Salvador. 1892, el IV Centenario del Descubrimiento de América en España: coyuntura y conmemoraciones. Madrid: CSIC, 1987.

Blanco, Alda. Cultura y conciencia imperial en la España del siglo XIX. Valencia: Universitat de València, 2012.

Bueno, Ángel. Historia de Colón por Los Autorcillos de Escrituras Libres, niños de 9 a 12 años, educandos de Ángel Bueno. Madrid: El Progreso Editorial, 1892.
Celdrán Gomáriz, Pancracio. Gran libro de los insultos. Madrid: La Esfera de los Libros, 2008.

Cervera, Juan. «En torno a la literatura infantil», Cance. Revista de Filología y su Didáctica, 12, (1989): 157-168.

Colón, Cristóbal. Los cuatro viajes del almirante y su testamento. Madrid: Espasa-Calpe, 1991.

Forster, E. M. Aspects of the novel. Harmondsworth: Penguin Books, 1972.

García Márquez, Gabriel. «Fantasía y creación artística», El País, (1981).

García Padrino, Jaime. Libros y literatura para niños en la España contemporánea. Madrid: Fundación Germán Sánchez Ruipérez / Pirámide, 1992.

Gerbi, Antonello. La disputa del Nuevo Mundo. Historia de una polémica 1750-1900. México: Fondo de Cultura Económica, 1982.

Hegel, G. W. F. Lecciones sobre la estética. Madrid: Akal, 1989.

Las Casas, Bartolomé de. Brevísima Relación de la destruición de las Indias. Alicante: Publicaciones Universidad de Alicante, 2006.

López Narváez, Concha. «Visión personal de la novela histórica y de su proceso de creación», Peonza, 38, (1996): 19-25.

López Narváez, Concha. Andanzas de Cristóbal Colón. Madrid: Bruño, 2006.

Manzano y Manzano, Juan. Colón y su secreto: el predescubrimiento. Madrid: Cultura Hispánica, 1928.

Méndez, Diego. Relación hecha por Diego Méndez, de algunos acontecimientos del último viage del Almirante don Cristóbal Colón. Martín Fernández de Navarrete (ed.). Colección de los viajes y descubrimientos que bicieron por mar los españoles desde fines del siglo XV, Tomo I. Madrid: Imprenta Real, 1825.

Menton, Seymour. La nueva novela bistórica de la América Latina (1979-1992). México: Fondo de Cultura Económica, 1993.

Merino, José María. «Pasado y novela». VV. AA., Corrientes actuales de la narrativa infantil y juvenil española en lengua castellana. Madrid: Asociación Española de Amigos del Libro Infantil y Juvenil, 1990.

Monreal, Violeta. El huevo de Colón. Madrid: Bruño, 2005. 
Morote Magán, Pascuala. «El cuento de tradición oral y el cuento literario: de la narración a la lectura». Antonio Mendoza Fillola (coord.). La seducción de la lectura en edades tempranas. [Madrid]: Secretaría General Técnica, Subdirección General de Información y Publicaciones, D. L., 2002: 159-197.

Muñoz Puelles, Vicente. El último manuscrito de Hernando Colón. Madrid: Anaya, 1992.

Muñoz Puelles, Vicente. jPolizón a bordo! (El secreto de Colón). Madrid: Anaya, 2013.

Paolucci, Antonio. «Ecco la prima immagine dei nativi americani raccontati da Colombo», L'osservatore romano: 27-04-2013.
Plaza, José María. ;Tierra a la vista!: la historia de Colón. Madrid: Espasa Calpe, 2005.

Plaza, José María. ¿Quién era Cristóbal Colón? Barcelona: Edebé, 2006.

Thaler, Danielle, y Jean Bart, Alain. Les Enjeux du roman pour adolescents. Roman historique, roman-miroir, roman d'anventures. Paris, L'Harmattan: 2002.

Todorov, Zvetan. La conquista de América. El problema del otro. Madrid, Siglo XXI, 2003.

Fecha de recepción: 15/05/2015

Fecha de aceptación: 15/10/2015 